\title{
Cardioprotective and Renoprotective Effects of the Use of SGLT2 Inhibitors in Diabetes Mellitus Patients
}

\author{
$1^{\text {st }}$ Linda Sukiatno \\ Pharmacy Program \\ Universitas Harapan Bangsa \\ Purwokerto, Indonesia \\ lindasukiatno1@gmail.com
}

\author{
$2^{\text {nd }}$ Ikhwan Yuda Kusuma \\ Pharmacy Program \\ Universitas Harapan Bangsa \\ Purwokerto, Indonesia \\ ikhwanyudakusuma@uhb.ac.id
}

\author{
$3^{\text {rd }}$ Galih Samodra \\ Pharmacy Program \\ Universitas Harapan Bangsa \\ Purwokerto, Indonesia \\ galihsamodra@uhb.ac.id
}

\begin{abstract}
Diabetes mellitus (DM) is a chronic disease due to the body's inability to use insulin effectively resulting in an increase in blood sugar. Optimal blood glucose control has an important role to prevent complications in DM sufferers. Complications such as cardiovascular and kidney disease can cause morbidity and mortality in people with DM. Therefore, the selection of drugs that can protect the heart and kidneys is needed. One alternative that has emerged recently is known as the sodium-glucose cotransporter-2 inhibitor (SGLT2 inhibitor) class of drug. This study was aimed to describe the cardioprotective and renoprotective effects of using SGLT2 inhibitors in DM patients. The method employed was a systematic review by searching online scientific journals in the PubMed, Science Direct and Google Scholar databases of 20102020. The findings revealed that the SGLT2 inhibitor class of drug had a better effect on a significant reduction in cardiovascular and renal event. The cardioprotective mechanism of SGLT2 inhibitors was related to sodiumhydrogen exchanger 1 (NHE1) in myocardium. While the renoprotective mechanism was related to the reduction of intraglomerular pressure. The conclusion is that SGLT2 inhibitors can provide cardioprotective effects such as reduced risk of MACE, myocardial infarction, heart failure, stroke, death from cardiovascular causes and renoprotective effects such as slowing the rate of albuminuria development, decreasing the incidence of serum creatinine doubling, progressively lowering levels of kidney replacement therapy, and slowing down in kidney function.
\end{abstract}

Keywords

SGLT2

inhibitor,

cardioprotective, renoprotective

\section{INTRODUCTION}

Diabetes Mellitus (DM) is a chronic disease that occurs either when the pancreas does not produce enough insulin or when the body cannot effectively use the insulin it produces [1]. The International Diabetes Federation (IDF) reports that the number of DM patients in the world in 2019 reaches 463 million $(9.3 \%)$ and is expected to increase $51 \%$ to 700 million $(10.9 \%)$ in 2045 with an age range of $20-79$ years. At present the number of people with DM in Indonesia is ranked seventh highest in the world [2]. Based on the results of the Republic of Indonesia Basic Health Research (Riskesdas) 2018, the prevalence of DM in Indonesia has increased from $6.9 \%$ in 2013 to $10.9 \%$ in 2018 [3].
Optimal blood glucose control has an important role to prevent complications in DM patients both macrovascular and microvascular. Macrovascular complication that can be caused by DM is like hypertension, while microvascular complication is as kidney disorder [4], [5]. Hypertension in people with DM can trigger and exacerbate the risk of cardiovascular disease, while kidney disorder can occur in $40 \%$ of people with DM and is a major cause of end-stage renal disease (ESRD) [6], [7], so it is necessary to choose drugs that can protect the heart and kidneys. One alternative that has emerged recently is known as the sodium-glucose cotransporter-2 inhibitor (SGLT2 inhibitor) which is a new oral antidiabetic that has been approved by the Food and Drug Administration (FDA) in 2018, so it still needs to be reviewed for its effectiveness [8]. In Indonesia, the SGLT2 inhibitor drug, dapagliflozin, has been approved by the National Agency for Drug and Food Control in 2018 [9]. SGLT2 inhibitors work by inhibiting glucose reabsorption in the proximal tubule and increasing its secretion through urine [10].

A meta-analysis conducted by Zelniker et al. revealed that the use of SGLT2 inhibitors reduced the risk of cardiovascular death or hospitalization for heart failure by $23 \%(p<0.0001)$ and reduced the incidence of major adverse cardiovascular events (MACE) by $11 \%(\mathrm{p}=0.0014)$ [11]. Another study conducted by Perkovic et al. showed that canagliflozin reduced the risk of kidney function decline by $40 \%$ in glomerular filtration rates (GFR), ESRD or kidney death [12]. Based on the two studies above, it can be seen that SGLT2 inhibitors have great potential as antihyperglycemia which have cardioprotective and renoprotective effects, so this study was aimed to describe the cardioprotective and renoprotective effects of using SGLT2 inhibitors in patients with diabetes mellitus.

\section{METHOD}

\section{A. Search Strategy}

This research is a systematic review described descriptively. Literature search in the form of international scientific journals published in 2010-2020 conducted online on the PubMed, Science Direct and Google Scholar databases by using the keywords "SGLT2 inhibitors", 
"SGLT2 inhibitors + cardioprotective", "SGLT2 inhibitors + renoprotective".

\section{B. Selection Criteria}

Selected scientific journals meet the inclusion criteria as follows: 1) clinical studies, 2) patients with diabetes mellitus with comorbid cardiovascular and renal disorders, 3) SGLT2 inhibitor drugs compared with controls (placebo) or other antidiabetic oral groups. On the other hand, the exclusion criteria are as follows: 1) inaccurate population (diabetic patients with liver diseases such as non-alcoholic fatty fatty disease [NAFLD]), 2) study design (review, experimental research).

\section{Data Extraction}

Data collection process uses data extraction methods with PICO (Population/Problem, Intervention, Comparison, Outcomes) approach. Forms of data synthesis that will be presented in a systematic review are identification, screening, eligibility, and included Synthesis of data is illustrated in the data flow diagram [13]. The research framework used is PICO.

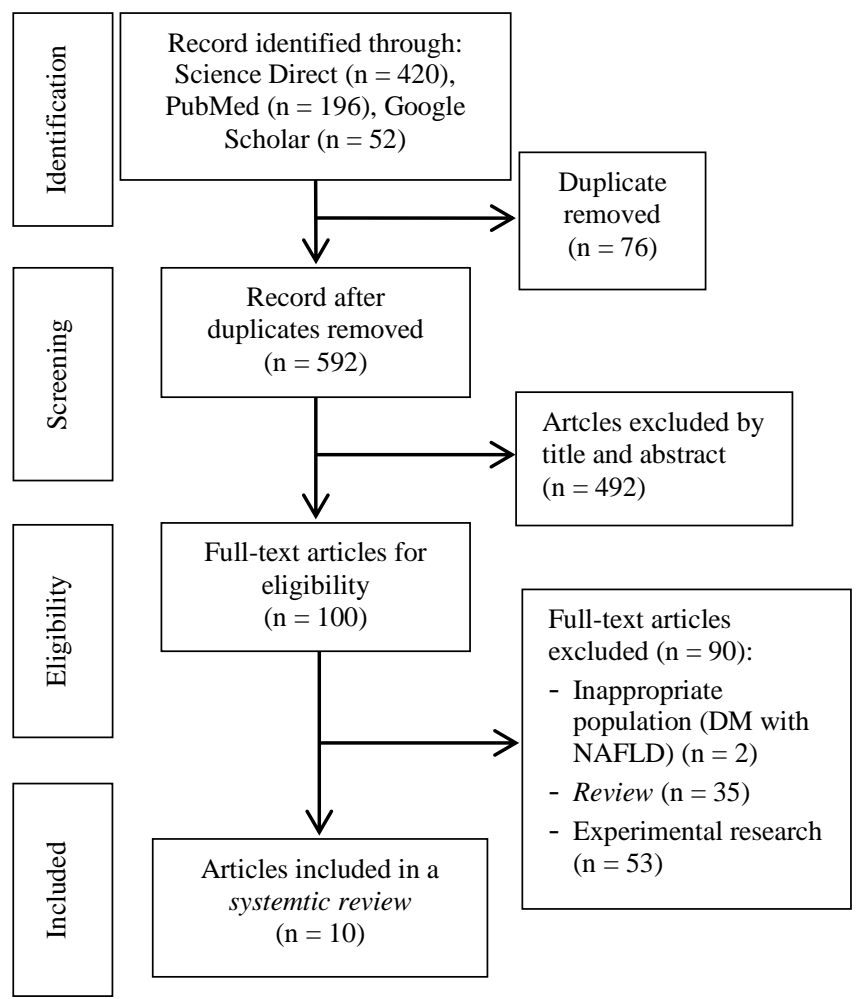

Fig. 1. Flow diagram of data result

TABLE I. RESEARCH FRAMEWORK

\begin{tabular}{lll}
\hline \multicolumn{1}{c}{ Criteria } & \multicolumn{1}{c}{ Inclusion } & \multicolumn{2}{c}{ Exclusion } \\
\hline $\begin{array}{l}\text { Population/ } \\
\text { Problem }\end{array}$ & $\begin{array}{l}\text { DM Patients with DM patients with liver } \\
\text { comorbid cardiovascular } \\
\text { and kidney disorders. }\end{array}$ & $\begin{array}{l}\text { DMeases such as non- } \\
\text { alcoholic fatty liver } \\
\text { disease (NAFLD). }\end{array}$ \\
\hline Intervention & $\begin{array}{l}\text { Monotherapy and } \\
\text { combination of SGLT2 } \\
\text { inhibitor therapy in DM } \\
\text { patients. }\end{array}$ \\
\hline Comparison & Control and other \\
\hline
\end{tabular}

\begin{tabular}{ll}
\hline & antidiabetic oral groups. \\
\hline Outcomes & The cardioprotective and \\
& renoprotective effects of \\
& $\begin{array}{l}\text { SGLT2 inhibitors in DM } \\
\text { patients. }\end{array}$ \\
\hline
\end{tabular}

\section{RESULT AND DISCUSSION}

Sodium-glucose cotransporter-2 inhibitors (SGLT2 inhibitors) are the latest oral drugs in the treatment of diabetes mellitus (DM). SGLT2 inhibitors work by inhibiting glucose reabsorption in the proximal tubule and increasing its secretion through urine [10]. Sodium-glucose cotransporter-2 (SGLT2) is located in the S1 segment of the renal proximal tubule and functions to put sodium and glucose back into the proximal tubule simultaneously (cotransporter) through an active transport mechanism [14].

Based on the results of a systematic review, it was found that various SGLT2 inhibitor drugs have been used in many clinical studies that provide cardioprotective and renoprotective effects in DM patients. Cardioprotective effects on cardiovascular outcomes such as major adverse cardiovascular events (MACE), myocardial infarction, heart failure, stroke, death from cardiovascular causes, are significantly reduced after SGLT2 inhibitor treatment in DM patients.

Treatment of SGLT2 inhibitors decreases MACE in DM patients. MACE has three main points, namely death from cardiovascular causes, non-fatal myocardial infarction and non-fatal stroke. A decrease in MACE was demonstrated in several clinical study results. Observational studies conducted by Birkeland et al. showed that type 2 DM patients with cardiovascular disorders using SGLT2 inhibitors (94\% dapagliflozin) had a lower risk of MACE compared to other antidiabetic drugs, with an incidence of $1.64 \%$ vs $2.12 \%$ respectively (HR $0.78 ; 95 \%$ CI; 0.69-0.87; $\mathrm{p}<0.0001)$ [15]. Similar results were also found in the Canagliflozin Cardiovascular (CANVAS) study conducted by Neal et al. showed that the use of canagliflozin 100 or 300 $\mathrm{mg}$ /day in type $2 \mathrm{DM}$ patients with cardiovascular disorders significantly reduced the risk of MACE compared to placebo, with an incidence of $26.9 \%$ in the empagliflozin group and $31.5 \%$ in the placebo group (HR 0.86; 95\% CI; 0.75-0.97; $p=0.02$ ) [16]. The reduced risk of MACE was also demonstrated in the Dapagliflozin Effect on Cardiovascular Events (DECLARE-TIMI58) study involving 17160 DM patients with type 2 who had atherosclerotic cardiovascular disease, with a 4.2-year study that the safety and efficacy of dapagliflozin $10 \mathrm{mg} /$ day were no worse than placebo in the incidence of MACE (8.8\% vs 9.4\%; $\mathrm{p}=0.14)$ [17].

Some studies also show that SGLT2 inhibitors reduce the risk of myocardial infarction. Canagliflozin Cardiovascular (CANVAS) study conducted by Neal et al. showed that canagliflozin 100 or $300 \mathrm{mg} /$ day reduced the risk of myocardial infarction in patients with type 2 DM who had cardiovascular disease compared with placebo, with an incidence of $9.7 \%$ vs $11.6 \%$ respectively (HR $0.85 ; 95 \% \mathrm{CI}$; 0.69-1.05; p=0.02) [16]. Whereas the Canagliflozin and Renal Events in Diabetes With Established Nephropathy Clinical Evaluation (CREDENCE) study by Mahaffey et al. showed results that type $2 \mathrm{DM}$ patients with cardiovascular and renal impairment, who were given canagliflozin therapy $100 \mathrm{mg} /$ day reduced the risk of myocardial infarction $12.5 \%$ 
lower than placebo $15.5 \%$ (HR 0.81; 95\% CI; 0.59-1.10; $\mathrm{p}=0.20$ ) [18]. Reduction in the risk of myocardial infarction also occurs in type $2 \mathrm{DM}$ patients who have atherosclerotic cardiovascular disease, with a lower incidence of myocardial infarction in the use of dapagliflozin $10 \mathrm{mg} /$ day by $4.6 \%$ compared to placebo at $5.1 \%$ (HR 0.89 95\% CI; 0.77-1.01) [17].

SGLT2 inhibitors also provide a reduction in the risk of hospitalization for heart failure. The Empagliflozin and Progression of Kidney Disease in Type 2 Diabetes (EMPAREG OUTCOME) study gave results in type $2 \mathrm{DM}$ patients with cardiovascular disorders treated with empagliflozin reducing the incidence of hospitalization for heart failure by $35 \% \quad$ (HR 0.65; 95\% CI; 0.50-0.85; p=0.002) [19]. Observational studies conducted on type 2 diabetes patients treated with SGLT2 inhibitors or other antidiabetic drugs, showed the use of SGLT2 inhibitors reduced hospitalization for heart failure (HR 0.70; 95\% CI; 0.61-0.81; p<0.0001) [15]. In patients with type $2 \mathrm{DM}$ who have atherosclerotic cardiovascular disease, dapagliflozin $10 \mathrm{mg}$ /day showed a significantly reduced rate compared to placebo $(4.9 \%$ vs $5.8 \%$; HR 0.83; 95\% CI, 0.73-0, 95; p=0.005) [17]. In addition, a study by Kato et al. which was aimed to find out the efficacy and safety of dapagliflozin according to the status of patients with heart failure and ejection fraction decreased, showing the results that dapagliflozin $10 \mathrm{mg} /$ day could reduce the risk of hospitalization in both patients with heart failure and ejection fraction decreased by $13.5 \%$ (HR $0.64 ; 95 \% \mathrm{CI} ; 0.43-0.95 ; \mathrm{p}=0.449$ ) and in patients without ejection fraction decreased by $2.1 \%$ (HR $0.76 ; 95 \%$ CI; $0.62-$ $0.92 ; \mathrm{p}=0.449)[20]$.

The reduction in the incidence of stroke in DM patients occurred after being treated with SGLT2 inhibitors. The CANVAS study by Neal et al. showed that canagliflozin 100 or $300 \mathrm{mg} /$ day reduced the risk of stroke by $7.1 \%$ compared to placebo by $8.4 \%$ (HR $0.90 ; 95 \% \mathrm{CI} ; 0.71-1.15$ ) [16]. Similar results were found in the CREDENCE study, this study showed that administration of canagliflozin $100 \mathrm{mg} /$ day in type $2 \mathrm{DM}$ patients with cardiovascular or renal impairments can reduce the rate of stroke that is lower by $9.3 \%$ compared to placebo by $11.7 \%$ (HR $0.80 ; 95 \%$ CI; $0.56-1.15 ; \mathrm{p}=0.14)$ [18].

Lower cardiovascular mortality rates occur in type $2 \mathrm{DM}$ patients treated with SGLT2 inhibitors as in the EMPA-REG OUTCOME study by Zinman et al. showed that type 2 DM patients with cardiovascular disorders, who received empagliflozin 10 or $25 \mathrm{mg} /$ day significantly reduced cardiovascular causes of death by $38 \%$ (HR $0.62 ; 95 \% \mathrm{CI}$; $0.49-0.77 ; \mathrm{p}<0.001$ ) [19]. On the other hand, type $2 \mathrm{DM}$ patients with cardiovascular disorders using SGLT2 inhibitors (94\% dapagliflozin) give lower cardiovascular death rates compared to other antidiabetic drugs (HR 0.53; 95\% CI; 0.40-0.71; p<0,0001) [15]. This was supported in the CANVAS study showing that administration of canagliflozin 100 or $300 \mathrm{mg} /$ day reduced the rate of cardiovascular deaths by $11.6 \%$ compared to placebo by $12.8 \%$ [16]. Decreased cardiovascular mortality also occurred in type $2 \mathrm{DM}$ patients with kidney and cardiovascular disease, who received canagliflozin 100 $\mathrm{mg}$ /day significantly reduced cardiovascular mortality by $19 \%$ compared to placebo by $24.4 \%$ (HR $0.78 ; 95 \%$ CI; $0.61-1.00 ; \mathrm{p}=0.86$ ) [18].
In addition to reviewing the cardioprotective effect in DM patients from the results of several clinical studies, the cardioprotective effect of SGLT2 inhibitors with potential mechanisms was obtained. SGLT2 inhibitors can have an effect in reducing inflammation. Inflammation is one of the mechanisms involved in the development of heart failure [21]. An experimental study conducted by Kusaka et al. mentioned that experimental animals (male SHR/NDmcr-cp $[+/+]$ mice) with the metabolic syndrome model showed empagliflozin treatment $(0.03 \%)$ for 10 weeks significantly reduced cardiac myocyte hypertrophy and interstitial fibrosis [22]. Lee et al. also reported in experiments on wistar rats with acute phase myocardial infarction models treated with dapagliflozin for 4 weeks, showing that dapagliflozin increased the activity of signal transducers and activators of transcription 3 (STAT3) mediated by reactive oxygen and nitrogen species (RONS) and increased activation M2 macrophages. M2 is an anti-inflammatory macrophage phenotype that will release interleukin (IL)-10. This IL-10 release can reduce myofibroblast filtration. Myofibroblast has a role in the development of cardiac fibrosis so that the administration of dapagliflozin can provide a heart repair effect through the STAT3 pathway (Figure 2) [23]

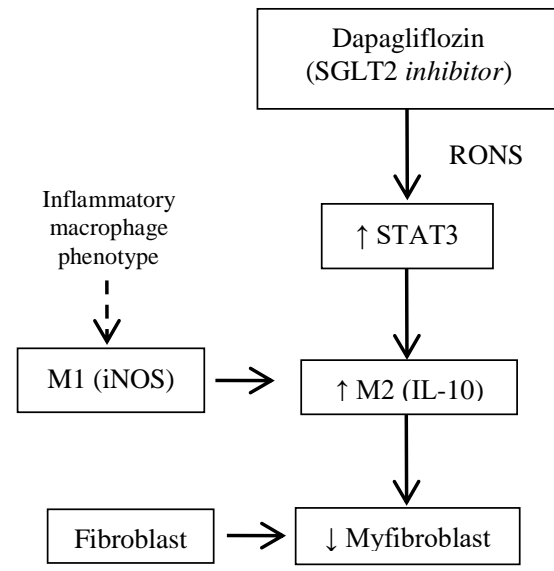

Fig. 2. Cardioprotective effect of SGLT2 inhibitors via the STAT3 pathway. RONS = reactive oxygen and nitrogen species, STAT3 = signal transducer and activator of transcription $3, \mathrm{M} 1=$ macrophage 1 , iNOS = superoxide and nitrotyrosine, M2 = macrophage $2, \mathrm{IL}-10=$ interleukin 10 [23].

SGLT2 inhibitors are associated with sodium-hydrogen exchanger (NHE) isoform 1. NHE1 is expressed in myocardium and modulates the $\mathrm{pH}$ of cardiomyocytes. Its activity is regulated in heart failure because it stimulates the neurohormonal system (norepinephrine, angiotensin and aldosterone), myocardial lactic acidosis and the occurrence of anaerobic metabolism in the heart. As a result, there is greater intracellular sodium $\left(\mathrm{Na}^{+}\right)$intake, which also activates sodium-calcium exchanger (NCX). This leads to an increase in intracellular calcium concentration which triggers cardiac remodeling (hypertrophy, fibrosis) through calcineurin activation which ultimately results in heart damage and cell death [24].

SGLT2 inhibitors inhibit NHE1 activity as evidenced by empagliflozin providing beneficial effects in DM patients with heart failure and reduced ejection fraction (HFrEF). HFrEF occurs in the presence of protein kinase B (AKT1-3 $[\mathrm{AKT} 1=\mathrm{RAC}$-alpha serine/threonine-protein kinase 1 ; AKT2 = RAC-beta serine/threonine-protein kinase 2; AKT3 
$=\mathrm{RAC}$-gamma serine/threonine-protein kinase 3]) which functions as an effector of NHE1 activation, NHE1 is responsible for the induction of baculoviral IAP repeatcontaining protein 2 (BIRC2) which will further induce $\mathrm{X}$ linked inhibitors of apoptosis (XIAP) and baculoviral IAP repeat-containing protein 5 (BIRC5) so that it will further induce the degradation of X-linked inhibitors of apoptosis (XIAP) and baculoviral IAP repeat-containing protein 5 (BIRC5) triggered the development of HFrEF. In the treatment of a post-infarct heart failure (MI-HF) mouse model, inhibition of NHE1 by empagliflozin, resulted in the inability of AKT1-3 and BIRC2 to reduce the XIAP and BIRC5 antiapoptotic factors thereby stopping the development of HFrEF (Figure 3) [25].

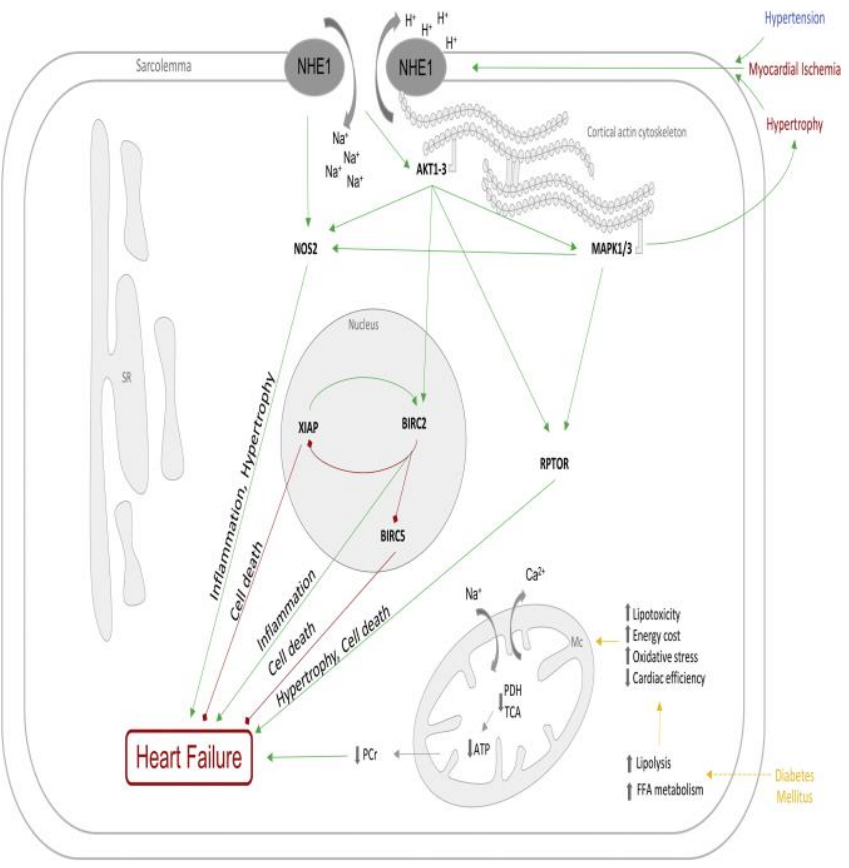

Fig. 3. Cardioprotective effect via the inhibition of NHE1 in myocardium, activation pathway (green arrow) and the inhibition (red arrow). AKT1 = RAC-alpha serine/threonine-protein kinase 1; AKT2 = RAC-beta serine/threonine-protein kinase 2; AKT3 = RAC-gamma serine/threonineprotein kinase $3 ; \mathrm{ATP}=$ adenosine triphosphate; $\mathrm{BIRC} 2=$ baculoviral IAP repeat-containing protein 2 ; BIRC5 $=$ baculoviral IAP repeatcontaining protein 5; LEP = leptin; MAPK1 = mitogen-activated protein kinase 1 ; MAPK3 = mitogen-activated protein kinase $3 ; \mathrm{MC}=$ mitochondria; NHE1 $=$ sodium/hydrogen exchanger $1 ;$ NOS2 = nitric oxide synthase; $\mathrm{PCr}=$ phosphocreatine; $\mathrm{PDH}=$ pyruvate dehydrogenase , RPTOR $=$ regulatoryassociated protein of $\mathrm{mTOR} ; \mathrm{SR}=$ sarcoplasmic reticulum; $\mathrm{TCA}=$ tricarboxylic acid; XIAP = X-linked inhibitor of apoptosis [25].

In addition to the cardioprotective effect, a renoprotective effect is also obtained from the use of SGLT2 inhibitors on kidney outcomes such as slowing the rate of albuminuria, decreasing the incidence of serum creatinine doubling, lowering levels of kidney replacement therapy, and slowing down in kidney function.

Based on the results of the EMPA-REG OUTCOME study conducted by Wanner et al. treatment with empagliflozin showed that type 2 DM patients experienced progression to macroalbuminuria by $11.2 \%$ compared to placebo by $16.2 \%$ (HR $0.62 ; 95 \%$ CI; $0.54-0.72 ; \mathrm{p}<0.001$ ) [26]. In addition to empagliflozin treatment, administration of canagliflozin 100 or $300 \mathrm{mg} /$ day in patients with type 2 $\mathrm{DM}$ can reduce urine albumin creatinine ratio (UACR) more on canagliflozin $100 \mathrm{mg}$ administration by $31.7 \%(\mathrm{p}=0.01)$ and canagliflozin $300 \mathrm{mg}$ by $49.3 \%$ ( $\mathrm{p}<0.001$ ) compared to glimepiride. The CANVAS study also showed a $27 \%$ reduction in albuminuria occurring in type 2 DM patients treated with canagliflozine (HR $0.73 ; 95 \%$ CI $0.67-0.69$ ) [16].

Type 2 DM patients with high cardiovascular risk were associated with a reduced risk of serum creatinine doubling by $44 \%$, with an incidence rate of $1.5 \%$ in the empagliflozin group and $2.6 \%$ in the placebo group (HR 0.56; $95 \% \mathrm{CI}$; 0.39-0.79; $\mathrm{p}<0.001$ ) [26]. Meanwhile, in the CREDENCE study by Mahaffey et al. showed that administration of canagliflozin had a doubling in the incidence of serum creatinine by $20.7 \%$ compared to a placebo of $33.8 \%$ [18].

In end-stage kidney disease, patients need dialysis therapy or kidney transplantation. Study by Wanner et al. showed a reduction in the incidence of renal replacement therapy by $55 \%$, with an incidence rate of $0.3 \%$ of patients in the empagliflozin group and $0.6 \%$ of patients in the placebo group (HR 0.45; 95\% CI; 0.21-0.97; $\mathrm{p}=0.04$ ) [26]. Whereas the CANVAS study showed a $40 \%$ reduction in glomerular filtration rate (GFR), renal replacement therapy, and death due to kidney causes (HR 0.60; 95\% CI; 0.47-0.77; $p=0.02$ ) [16].

Studies conducted by Heerspink et al. showed that administration of canagliflozin 100 or $300 \mathrm{mg} /$ day could slow the decline in kidney function for more than two years in patients with type $2 \mathrm{DM}$ compared with glimepiride administration. Decreased GFR by $3.3 \mathrm{ml} / \mathrm{min} / 1.73 \mathrm{~m} 2 /$ year in the glimepiride group; $0.5 \mathrm{ml} / \mathrm{min} / 1.73 \mathrm{~m} 2 /$ year in the 100 mg canagliflozin group; and $0.9 \mathrm{ml} / \mathrm{min} / 1.73 \mathrm{~m} 2 /$ year in the $300 \mathrm{mg}$ canagliflozin group $(\mathrm{p}=0.01)$ [27]. In the study of Perkovic et al. also showed canagliflozin decreased GFR compared to the placebo group $(3.19 \pm 0.15$ vs $4.71 \pm 0.15$ $\mathrm{ml} / \mathrm{min} / 1.73 \mathrm{~m} 2$ ) [28]. In addition to canagliflozin, empagliflozin administration in patients with type $2 \mathrm{DM}$ high cardiovascular risk decreased annual GFR by $0.19 \pm 0.11$ $\mathrm{ml} / \mathrm{min} / 1.73 \mathrm{~m} 2$ in empagliflozin users compared to placebo by $1.67 \pm 0.13 \mathrm{ml} / \mathrm{min} / 1.73 \mathrm{~m} 2 \quad(\mathrm{p}<0.001) \quad$ [26]. A retrospective cohort study conducted by Sugiyama et al. It was also found that treatment with SGLT2 inhibitors had an annual decreasing effect on GFR and urinary protein-tocreatinine ratio (UPCR) in patients with type $2 \mathrm{DM}$ with chronic kidney disease (CKD) stage 3b-4 (GFR: pre: -3.8 vs post: $0.1 \mathrm{ml} / \mathrm{min} / 1.73 \mathrm{~m} 2 /$ year, $\mathrm{p}<0.01$ and pre UPCR: 0.36 vs post: $0.23 \mathrm{mg} / \mathrm{g}$ Cre/year, $\mathrm{n}=35, \mathrm{p}<0.01$ ) [29].

The renoprotective effect of SGLT2 inhibitors also has a potential mechanism. SGLT2 inhibitors cause excretion of glucose and sodium $(\mathrm{Na}+)$ in the urine. The presence of glucose reabsorption is bound to $\mathrm{Na}+$ absorption, so there is an increase in $\mathrm{Na}+$ in the macula densa thereby increasing tubuloglomerular feedback activation which causes vasoconstriction of afferent arterioles, which is triggered mainly by the adenosine mediated signal cascade. Macula densa inhibits renin release from juxtaglomerular cells, an increase in dilatation of efferent arterioles. Afferent arteriolar vasoconstriction and efferent arteriolar dilatation decrease intraglomerular pressure. Reduced intraglomerular pressure can cause a decrease in albuminuria and glomerular filtration rate (Figure 4) [14], [27]. 
In addition to the mechanism of reduced intraglomerular pressure, SGLT2 inhibitors reduce the activity of sodiumhydrogen exchanger (NHE) isoform 3 in the kidney. This NHE3 activity mediates sodium reuptake. Reduction of NHE3 activity by SGLT2 inhibitors causes an increase in natriuresis. Increased natriuresis will activate tubuloglomerular feedback to reduce intraglomerular pressure and hyperfiltration resulting in a decrease in single nephron glomerular filtration rate (SNGFR). The process can also provide other effects such as reducing hyperuricemia, diuresis, calorie loss and glucosuria. The decrease in hyperuricemia occurs with an increase in luminal glucose can facilitate intracellular urate exchange through glucose transporter-9 (GLUT9) so that uric acid excretion occurs in the urine. Diuresis and calorie loss result in weight loss and blood pressure, which then increases insulin sensitivity and decreases arterial stiffness. The occurrence of glucosuria, will reduce hyperglycemia and reduce glucotoxicity (Figure 5) [24], [30].

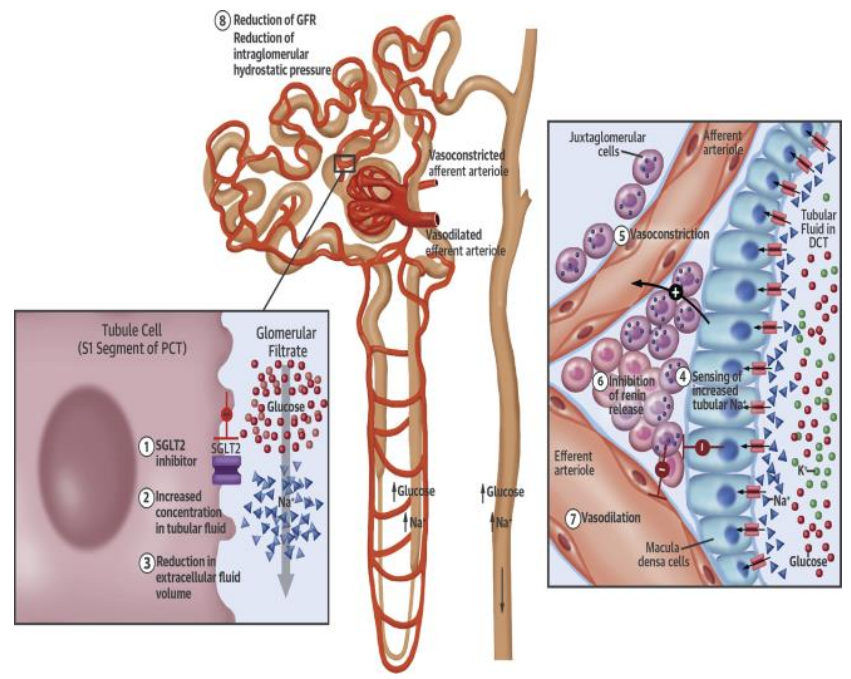

Fig. 4. The mechanism of renoprotective effects in reducing intraglomerular pressure. DCT = distal convoluted tubule; $\mathrm{K}^{+}=$potassium; $\mathrm{PCT}=$ proximal convoluted tubule [14].

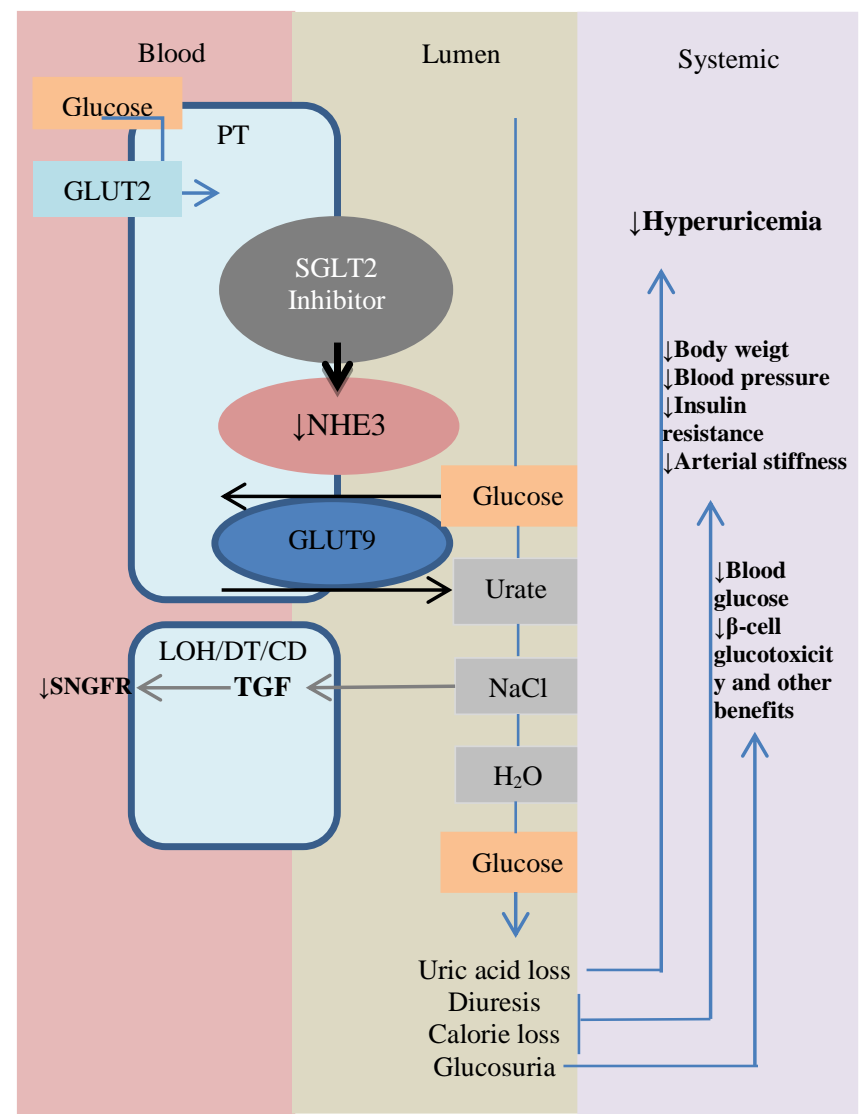

Fig. 5. The mechanism of renoprotective effects in reducing NHE3 activity in the kidneys. $\mathrm{PT}=$ proximal tubule, $\mathrm{LOH}=$ loop of Henle, $\mathrm{DT}=$ distal tubule, $\mathrm{CD}=$ collecting duct, $\mathrm{SGLT}=$ sodium-dependent glucose transporter GLUT = glucose transporter; NHE3 = sodium hydrogen exchanger-3 [30].

Based on the description above, it is found that the use of SGLT2 inhibitors from clinical study results shows a significant reduction in risk factors for cardiovascular events such as risk of MACE, myocardial infarction, heart failure, stroke, death from cardiovascular causes. The cardioprotective effect of SGLT2 inhibitors appears by reducing inflammation in the heart through the STAT3 pathway and through the mechanism of NHE1 inhibition in myocardium can prevent the occurrence of HFrEF. Besides having a cardioprotective effect, SGLT2 inhibitors also have a renoprotective effect. The results of clinical studies also found a reduction in kidney events such as slowing the rate of development of albuminuria, decreasing the incidence of serum creatinine which doubled, lower levels of kidney replacement therapy, and slowing the decline in kidney function. Renoprotective effects arise by lowering intraglomerular pressure which causes vasoconstriction of afferent arterioles so as to reduce albuminuria levels and glomerular filtration rate. This, also supported by a reduction in NHE3 activity by SGLT2 inhibitors, causes an increase in natriuresis thereby activating tubuloglomerular feedback to reduce intraglomerular pressure.

\section{CONCLUSION}

SGLT2 inhibitors are a new class of antihyperglycemic agents with potential cardioprotective and renoprotective effects. The cardioprotective effect of using SGLT2 inhibitors can reduce the risk of MACE, myocardial 
infarction, heart failure, stroke, death from cardiovascular causes. While the renoprotective effect of using SGLT2 inhibitors can slow the rate of albuminuria development, decrease the incidence of serum creatinine doubled, the lower the level of renal replacement therapy, and slow the decline in kidney function. This drug has a cardioprotective mechanism associated with reducing inflammation in the heart through the STAT3 pathway and through inhibition of NHE1 in the myocardium can prevent the occurrence of HFrEF. On the other hand, the renoprotective mechanism is related to the reduction of intraglomerular pressure which can reduce albuminuria levels and glomerular filtration rate and is supported by a reduction in NHE3 activity in the kidneys.

\section{ACKNOWLEDGMENT}

The researchers would like to thank the Advisor and all academic community of Harapan Bangsa University in Purwokerto, as well as Yogyakarta Aisyiyah University as the organizer of this activity.

\section{REFERENCES}

[1] WHO, Global Report on Diabetes. France: World Health Organization, 2016.

[2] IDF, IDF Diabetes Atlas Ninth edition 2019. BELGIUM: International Diabetes Federation, 2019.

[3] Kemenkes, Laporan Nasional RISKESDAS 2018. Jakarta: Balitbang Kemenkes Republik Indonesia, 2018.

[4] A. Luman, "Peran Inhibitor Sodium Glucose Cotransporter 2 (SGLT2) pada Terapi Diabetes Melitus," CKD 230, vol. 42, no. 7, pp 498-503, 2015.

[5] L. Nurayati and M. Adriani, "Hubungan Aktifitas Fisik dengan Kadar Gula Darah Puasa Penderita Diabetes Melitus Tipe 2," Amerta Nutr., pp. 80-87, 2017.

[6] R.Z. Alicic., M.T. Rooney., and K.R. Tuttle, "Diabetic Kidney Disease," Clin J Am Soc Nephrol, vol. 12, no. 18, pp. 2032-2045, 2017

[7] C. Cheung, B.M.Y and Li, "Diabetes and Hypertension: Is There a Common Metabolic Pathway?," Curr Atheroscler Rep, vol. 14, pp. $160-166,2012$

[8] D.K. McGuire., N. Marx., O.E. Johansen., S.E. Inzucchi., J Rosenstock., and J.T. George, "FDA guidance on antihyperglycemic therapies for type 2 diabetes: One decade later," Diabetes Obes Metab, vol. 21, pp. 1073-1078, 2019.

[2] BPOM, "DAPAGLIFLOZIN," AVAILABLE AT: HTTPS://CEKBPOM.POM.GO.ID/INDEX.PHP/HOME/PRODUK/MPI8S5SFD1 KHP5JR7LB8FGCH32/ALL/ROW/10/PAGE/0/ORDER/4/DESC/SEARCH/5/ DAPAGLIFLOZIN. ACCESSED JUNE 14, 2020

[1] WHO, Global Report on Diabetes. France: World Health Organization, 2016.

[2] IDF, IDF Diabetes Atlas Ninth edition 2019. BELGIUM: International Diabetes Federation, 2019.

[3] Kemenkes, Laporan Nasional RISKESDAS 2018. Jakarta: Balitbang Kemenkes Republik Indonesia, 2018.

[4] A. Luman, "Peran Inhibitor Sodium Glucose Cotransporter 2 (SGLT2) pada Terapi Diabetes Melitus," CKD 230, vol. 42, no. 7, pp. 498-503, 2015.

[5] L. Nurayati and M. Adriani, "Hubungan Aktifitas Fisik dengan Kadar Gula Darah Puasa Penderita Diabetes Melitus Tipe 2," Amerta Nutr., pp. 80-87, 2017.

[6] R.Z. Alicic., M.T. Rooney., and K.R. Tuttle, "Diabetic Kidney Disease," Clin J Am Soc Nephrol, vol. 12, no. 18, pp. 2032-2045, 2017.

[7] C. Cheung, B.M.Y and Li, "Diabetes and Hypertension: Is There a Common Metabolic Pathway?," Curr Atheroscler Rep, vol. 14, pp. $160-166,2012$
[8] D.K. McGuire., N. Marx., O.E. Johansen., S.E. Inzucchi., J. Rosenstock., and J.T. George, "FDA guidance on antihyperglycemic therapies for type 2 diabetes: One decade later," Diabetes Obes Metab, vol. 21, pp. 1073-1078, 2019.

[9] BPOM, "Dapagliflozin," Available at: https://cekbpom.pom.go.id/index.php/home/produk/mpi8s5sfd1khp5jr 7lb8fgch32/all/row/10/page/0/order/4/DESC/search/5/dapagliflozin. Accessed June 14, 2020

[10] J. Wilding., K. Fernando., N. Milne., M. Evans., A. Ali., S. Bain., D. Hicks., J. James., P.N. Jones., and A. Viljoen, "SGLT2 Inhibitors in Type 2 Diabetes Management: Key Evidence and Implications for Clinical Practice,” Diabetes Ther., vol. 9, no. 5, pp. 1757-1773, 2018.

[11] T.A. Zelniker, T.A., S.D. Wiviott., I. Raz., K. Im., E.L. Goodrich., M.P. Bonaca., O. Mosenzon., E.T. Kato., A. Cahn., R.H.M. Furtado., D.L. Bhatt., L.A. Leiter., D.K. McGuire., J.P.H. Wilding., and M.S. Sabatine, "SGLT2 inhibitors for primary and secondary prevention of cardiovascular and renal outcomes in type 2 diabetes: a systematic review and meta-analysis of cardiovascular outcome trials," Lancet, vol. 393, no. 10166, pp. 31-39, 2019.

[12] V. Perkovic., D.de. Zeeuw., K.W. Mahaffey., G. Fulcher., N. Erondu., W. Shaw., T.D. Barrett., M.W. Wells., H. Deng., D.R. Matthews., and B. Neal, "Canagliflozin and renal outcomes in type 2 diabetes : results from the CANVAS Program randomized clinical trials," Lancet Diabetes Endocrinol., vol. 8587, no. 18, pp. 1-13, 2018.

[13] D. Moher., A. Liberati., J. Tetzlaff., and D.G. Altman, "Preferred reporting items for systematic reviews and meta-analyses: the PRISMA statement,” BMJ, vol. 339, pp. 332-336, 2009.

[14] E. Zelniker, T.A \& Braunwald, "Cardiac and Renal Effects of Sodium-Glucose Co-Transporter 2 Inhibitors in Diabetes," J. Am. Coll. Cardiol., vol. 72, no. 15, pp. 1845-1855, 2018.

[15] K.I. Birkeland., M..E. Jorgensen., B. Carstensen., F. Persson., H.L. Gulseth., M. Thuresson., P. Fenici., D. Nathanson., T. Nystrom., J.W. Eriksson., J. Bodegard., and A. Norhammar, "Articles Cardiovascular mortality and morbidity in patients with type 2 diabetes following initiation of sodium-glucose co-transporter-2 inhibitors versus other glucose-lowering drugs ( CVD-REAL Nordic ): a multinational observational analysis," Lancet Diabetes Endocrinol, vol. 2, no. 17, pp. 1-9, 2017.

[16] B. Neal., V. Perkovic., K.W. Mahaffey., D.de. Zeeuw., G. Fulcher., N.Erondu., W. Shaw., G. Law., M. Desai., and D.R. Matthews, "Canagliflozin and Cardiovascular and Renal Events in Type 2 Diabetes,” N. Engl. J. Med., vol. 377, pp. 1-14, 2017.

[17] S.D. Wiviott., I. Raz., M.P. Bonaca., O. Mosenzon., E.T. Kato., A. Cahn., M.H. Silverman., T.A. Zelniker., J.F. Kuder., S.A. Murphy., D.L. Bhatt., L.A. Leiter., D.K. McGuire., J.P.H. Wilding., C.T. Ruff., I.A.M. Gause-Nilson., M. Fredriksson., P.A. Johansson., A.M. Langkilde., and M.S. Sabatine, "Dapagliflozin and Cardiovascular Outcomes in Type 2 Diabetes," N. Engl. J. Med., vol. 380, pp. 347357, 2019.

[18] K.W. Mahaffey., M.J. Jardine., S. Bompoint., C.P. Cannon., B. Neal., H.J.L. Heerspink., D.M. Charytan., R. Edwards., R. Agarwal., G. Bakris., S. Bull., G. Capuano., D. de. Zeeuw., T. Greene., A. Levin., C. Pollock., T. Sun., D.C. Wheeler., Y. Yavin., H. Zhang., B. Zinman., N. Rosenthal., B.M. Brenner., and V.G. Perkovic, "Canagliflozin and Cardiovascular and Renal Outcomes in Type 2 Diabetes Mellitus and Chronic Kidney Disease in Primary and Secondary Cardiovascular Prevention Groups," Circulation, vol. 140, pp. 739-750, 2019.

[19] B. Zinman., C. Wanner., J.M. Lachin., D. Fitchett., E. Bluhmki., S. Hantel., M. Mattheus., T. Devins., O.E. Johansen., H.J. Woerle., U.C. Broedl., and S.E. Inzucchi, "Empagliflozin, Cardiovascular Outcomes, and Mortality in Type 2 Diabetes,” N. Engl. J. Med., vol. 373, pp. 1-12, 2015.

[20] E.T. Kato., M.G. Silverman., O. Mosenzon., T.A. Zelniker., A. Cahn., R.H.M. Furtado., J. Kuder., S.A. Murphy., D.L. Bhatt., L.A. Leiter, D.K. McGuire., J.P.H. Wilding., M.P. Bonaca., C.T. Ruff., A.S. Desai., S. Goto., P.A. Johansson., I.G. Nilsson., P. Johanson., A.M. Langkilde., I. Raz., M. S. Sabatine., and S.D. Wiviott, "Effect of Dapagliflozin on Heart Failure and Mortality in Type 2 Diabetes Mellitus," Circulation, vol. 139, pp. 2528-2536, 2019.

[21] J.L. Mehta., and N.V.K. Pothineni, "Inflammation in Heart Failure The Holy Grail?," Hypertension, vol. 68, pp. 27-29, 2016. 
[22] H. Kusaka., N. Koibuchi., Y. Hasegawa., H. Ogawa., and S.K Mitsuyama, "Empagliflozin lessened cardiac injury and reduced visceral adipocyte hypertrophy in prediabetic rats with metabolic syndrome," Cardiovasc. Diabetol., vol. 15, no. 157, pp. 1-14, 2016.

[23] T.M. Lee., N.C. Chang., and S.Z. Lin, "Dapagliflozin, a selective SGLT2 Inhibitor, attenuated cardiac fibrosis by regulating the macrophage polarization via STAT3 signaling in infarcted rat hearts," Free Radic. Biol. Med., vol. 104, pp. 298-310, 2017.

[24] M. Packer, "Activation and Inhibition of Sodium-Hydrogen Exchanger Is a Mechanism That Links the Pathophysiology and Treatment of Diabetes Mellitus With That of Heart Failure," Circulation, vol. 136, pp. 1548-1559, 2017.

[25] O. Iborra-Egea., E.S. Vacas., S.R.Yurista., J. Lupon., M. Packer., S. Heymans., F. Zannad., J. Butler., D.P. Figal., A. Lax., J. Nunez., R.A.de. Boer., and A. Bayés-Genís, "Unraveling the Molecular Mechanism of Action of Empagliflozin in Heart Failure With Reduced Ejection FractionWith or Without Diabetes," J Am Coll Cardiol Basic Trans Sci., 2019.

[26] C. Wanner., S.E. Inzucchi., J.M. Lachin., D. Fitchett., M.von. Eynatten., M. Mattheus., O.E. Johansen., H.J. Woerle., U.C. Broedl., and B. Zinman, "Empagliflozin and Progression of Kidney Disease in Type 2 Diabetes," N. Engl. J. Med., vol. 375, pp. 323-334, 2016.

[27] H.J.L. Heerspink., M. Desai., M. Jardine., D. Balis., G. Meininger., and V. Perkovic, "Canagliflozin Slows Progression of Renal Function Decline Independently of Glycemic Effects," J Am Soc Nephrol, vol. 28, pp. 1-8, 2016.

[28] S. Perkovic, V., Jardine, M.J., Neal, B., Bompoint, S., Heerspink, H.J.L., Charytan, D.M., Edwards, R., Agarwal, R., Bakris, G., Bull, "Canagliflozin and Renal Outcomes in Type 2 Diabetes and Nephropathy,” N. Engl. J. Med., vol. 380, pp. 2295-2306, 2019.

[29] S. Sugiyamaa., H. Jinnouchia., A. Yoshidaa., K. Hieshimaa., N. Kurinamia., K. Jinnouchia., M. Tanakai., T. Suzukia., F. Miyamotoa., K. Kajiwaraa., and Jinnouchia, "Renoprotective Effects of Additional SGLT2 inhibitor Therapy in Patients With Type 2 Diabetes Mellitus and Chronic Kidney Disease Stages 3b-4 : A Real World Report From A Japanese Specialized Diabetes Care Center," J Clin Med Res, vol. 11, no. 4, pp. 267-274, 2019.

[30] L.A. Gallo., E.M. Wright., and V. Vallon, "Probing SGLT2 as a therapeutic target for diabetes: basic physiology and consequences," Diabetes Vasc. Dis. Res., vol. 12, no. 2, pp. 78-79, 2015 